\title{
Glucagon-like peptide 1 regulates adipogenesis in 3T3-L1 preadipocytes
}

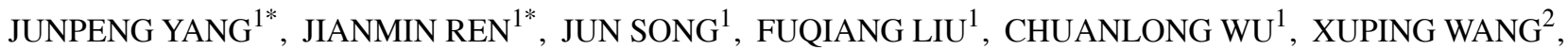 \\ LEI GONG ${ }^{1}$, WENJUAN LI ${ }^{1}$, FANG XIAO ${ }^{1}$, FEI YAN ${ }^{1}$, XINGUO HOU $^{1}$ and LI CHEN ${ }^{1}$ \\ ${ }^{1}$ Department of Endocrinology of Qilu Hospital and Institute of Endocrinology and Metabolism, Shandong University, Jinan, \\ Shandong; ${ }^{2}$ The Key Laboratory of Cardiovascular Remodeling and Function Research, Chinese Ministry of Education \\ and Chinese Ministry of Public Health, Shandong University, Qilu Hospital, Jinan, Shandong, P.R. China
}

Received January 28, 2013; Accepted March 18, 2013

DOI: $10.3892 / \mathrm{ijmm} .2013 .1350$

\begin{abstract}
Glucagon-like peptide 1 (GLP-1), a gut-derived peptide, has been reported to have profound effects on metabolism and to reduce insulin resistance. Adipocyte hyperplasia stimulated by preadipocyte differentiation has a positive effect on adipose tissue insulin sensitivity. However, it remains less clear whether GLP-1 plays a role in adipogenesis. In this study, we examined the effect of GLP-1 on preadipocyte differentiation and investigated the mechanisms that may be involved in this effect. In our 3T3-L1 cell study, we tested the levels of adipocyte-specific markers and signaling pathways during preadipocyte differentiation. In addition, Oil Red O staining was used to examine lipid accumulation. Image Pro Plus 5.02 was used to analyze the size and number of lipid droplets. We found that GLP-1 elevated the protein expression levels of free fatty acid-binding protein 4 (aP2) and the transcription factor peroxisome proliferator-activated receptor- $\gamma(\operatorname{PPAR}-\gamma)$ in a dose-dependent manner during 3T3-L1 preadipocyte differentiation. Furthermore, RT-PCR results showed that GLP-1 promoted CCAAT/enhancer-binding protein $\alpha(\mathrm{C} / \mathrm{EBP} \alpha)$ and lipoprotein lipase (LPL) expression at the transcriptional level. These data suggest that GLP-1 promotes preadipocyte differentiation. Our study also found that treatment of the cells with 100 nM GLP-1 enhanced the phosphorylation of Akt signaling during the first $24 \mathrm{~h}$ of differentiation. Although Oil Red O staining showed that GLP-1 had no significant effect on lipid accumulation, there were increased numbers of small adipocytes in the cells treated with 100 nM GLP-1. Taken
\end{abstract}

Correspondence to: Dr Li Chen or Dr Xinguo Hou, Department of Endocrinology of Qilu Hospital and Institute of Endocrinology and Metabolism, Shandong University, No. 107 Wenhua Xi Road, Jinan, Shandong 250012, P.R. China

E-mail: chenli3@medmail.com.cn

E-mail: houxinguo@medmail.com.cn

*Contributed equally

Key words: glucagon-like peptide 1, adipogenesis, Akt together, these results indicate that GLP-1 regulates 3T3-L1 adipogenesis and the Akt signaling pathway may be involved in this process. The differentiated small adipocytes may have a positive effect against insulin resistance and obesity.

\section{Introduction}

The growing prevalence of obesity constitutes a major health problem worldwide (1). Obesity, particularly abdominal obesity, has a strong relationship with insulin resistance and is a major risk factor for type 2 diabetes and cardiovascular disease $(2,3)$. The imbalance between energy intake and expenditure contributes to the development of obesity $(1,4)$; the cellular mechanisms for which include the expansion of white adipose tissue via the hypertrophy of preexisting adipocytes and hyperplasia resulting from the adipogenesis of preadipocytes $(4,5)$. When animals are maintained on a highfat diet, adipocyte cell size initially increases, followed by an increase in fat cell number upon prolonged over-nutrition (6). In adults, $\sim 10 \%$ of fat cells are renewed from preadipocytes annually (7). One study in adults demonstrated that short-term overfeeding increases the adipocyte cell numbers (8). Thus, adipogenesis probably has a role in the pathology of obesity in human adults. However, there are significant differences in lipid and glucose metabolism between adipocyte hypertrophy and hyperplasia (9-11). Recent studies have shown that adipocyte hypertrophy is negatively correlated with dyslipidemia and insulin resistance, independent of body composition $(9,11)$. Notably, hyperplasia, which is characterized by an increased number of small subcutaneous adipocytes, may have a positive effect on lipid metabolism and insulin sensitivity through preadipocyte differentiation $(9,10)$. Therefore, improving the characteristics of adipocytes may have therapeutic potential for treating obesity and insulin resistance.

Glucagon-like peptide 1 (GLP-1), which is secreted from intestinal L-cells following nutrient ingestion, exerts multiple biological effects through the GLP-1 receptor (GLP-1R) such as enhancing glucose-dependent insulin secretion, reducing glucagon levels, inhibiting the gastric emptying rate and increasing pancreatic $\beta$-cell proliferation $(12,13)$. Moreover, GLP-1 also increases insulin sensitivity in liver, muscle and adipocyte models (14-16). Furthermore, recent studies have 
revealed that GLP-1 improves insulin sensitivity in adipocytes by upregulating the expression of insulin receptor and Glut-4 (16), reducing macrophage infiltration and inhibiting inflammatory adipocytes (17). Boc5 (a GLP-1R agonist) also significantly reduced fat mass and adipocyte hypertrophy in an animal model of obesity (18). However, the effect of GLP-1 on adipogenesis is less clear.

In this study, using 3T3-L1 preadipocytes, we examined the effect of GLP-1 on preadipocyte differentiation and investigated the mechanisms that could be involved in this effect.

\section{Materials and methods}

Cell culture and treatment. 3T3-L1 preadipocytes (CL-173 ${ }^{\mathrm{TM}}$; ATCC) were cultured in Dulbecco's modified Eagle's medium (DMEM) (Invitrogen, Carlbad, CA, USA) containing 10\% fetal bovine serum (FBS) and $10 \mathrm{mg} / \mathrm{ml}$ penicillin/streptomycin in an atmosphere of $10 \% \mathrm{CO}_{2}$ at $37^{\circ} \mathrm{C}$. Two days after the 3T3-L1 preadipocytes reached confluence, differentiation was induced by culture with $0.5 \mathrm{mmol} / 13$-isobutyl-1-methylxanthine (IBMX), $1 \mu \mathrm{M}$ dexamethasone (DEX), $5 \mu \mathrm{g} / \mathrm{ml}$ insulin (SigmaAldrich, St. Louis, MO, USA) and 10\% FBS in DMEM for $48 \mathrm{~h}$. The cell culture medium was then replaced with DMEM containing $5 \mu \mathrm{g} / \mathrm{ml}$ insulin and 10\% FBS for an additional $48 \mathrm{~h}$. The cells were fed DMEM containing 10\% FBS every other day for the next 5-8 days, and at day 8, $>90 \%$ of the cells demonstrated an adipocyte phenotype. Recombinant human glucagon-like peptide (7-36) GLP-1 (Huayi BIO-Lab Co., Shanghai, China) was added to the culture medium at different concentrations during the adipogenic period of 8 days.

MTT cell viability assay. The 3T3-L1 preadipocytes were seeded into 96 -well culture plates at a density of $6 \times 10^{5}$ cells/well. GLP-1 was added to the medium at different concentrations and was then incubated with the cells for $48 \mathrm{~h}$. Subsequently, the medium was replaced with $100 \mu \mathrm{l} \mathrm{FBS-free} \mathrm{DMEM} \mathrm{and}$ the cells were incubated with $5 \mathrm{mg} / \mathrm{ml}$ MTT solution for $4 \mathrm{~h}$ at $37^{\circ} \mathrm{C}$. Next, the medium was removed, and the cells were solubilized in DMSO (Huayi BIO-Lab Co.). The absorbance at $490 \mathrm{~nm}$ was measured using a spectrophotometer (Varioskan Flash; Thermo Fisher Scientific, Inc., Waltham, MA, USA).

Quantitative real-time PCR. Total RNA was extracted, and the concentrations were measured using a spectrophotometer (Bio-Rad, Hercules, CA, USA). A total of $1 \mu \mathrm{g}$ mRNA was reverse-transcribed into cDNA and was amplified using the SYBR-Green I reagent (Takara, Tokyo, Japan) in a fluorescence thermocycler (LightCycler; Roche Diagnostics, Mannheim, Germany). Mouse $\beta$-actin was used as an internal control. The sequences of the primers used in the study were as follows: peroxisome proliferator activated receptor- $\gamma$ (PPAR- $\gamma$ ), 5'-GTG AAG CCC ATC GAG GAC A-3' (forward) and 5'-TGG AGC ACC TTG GCG AAC A-3' (reverse); CCAAT/enhancerbinding protein $\alpha(\mathrm{C} / \mathrm{EBP} \alpha), 5^{\prime}-\mathrm{GCG}$ GGA ACG CAA CAA CAT C-3' (forward) and 5'-GTC ACT GGT CAA CTC CAG CAC-3' (reverse); lipoprotein lipase (LPL), 5'-TGT AAC AAT CTG GGC TAT GAG ATC AAC-3' (forward) and 5'-TGC TTG CCA TCC TCA GTC CC-3' (reverse); free fatty acid binding protein 4 (aP2), 5'-AGG CTC ATA GCA CCC TCC TGT G-3' (forward) and 5'-CAG GTT CCC ACA AAG GCA TCA C-3' (reverse); and $\beta$-actin, 5'-GTG ACG TTG ACA TCC GTA AAG A-3' (forward) and 5'-GCC GGA CTC ATC GTA CTC C-3' (reverse). Target gene mRNA levels were normalized to those of $\beta$-actin using the $2^{-\Delta \Delta \mathrm{CT}}$ method.

Western blot analysis. Total protein was extracted and then quantified using a BCA protein quantification kit (Beyotime, Shanghai, China). A total of $30 \mu \mathrm{g}$ protein from each sample was separated by SDS-PAGE (10-15\%) and transferred to a polyvinylidene difluoride membrane $(0.22-\mu \mathrm{m}$ pore size; Millipore, Billerica, MA, USA). The membranes were blocked in 5\% non-fat milk in TBS-T for $2 \mathrm{~h}$ at room temperature. After incubation with the primary antibodies at $4^{\circ} \mathrm{C}$ overnight, the membranes were washed extensively with TBS-T prior to incubation with the secondary anti-rabbit/mouse horseradish peroxidase-conjugated antibody (Beijing Zhongshan Gold Bridge Biotechnology Co., Beijing, China) for $2 \mathrm{~h}$ at room temperature. After the membranes were washed again with TBS-T, the bands were visualized with enhanced chemiluminescence reagents (Millipore). Primary antibodies against mouse PPAR- $\gamma$, aP2, $\beta$-actin, phospho-Akt, Akt, phosphoP38, P38, phospho-ERK1/2 and ERK1/2 (Cell Signaling Technology, Danvers, MA, USA) were used.

Oil Red $O$ staining and lipid content quantification. The cellular lipid content was assessed by Oil Red O staining (Sigma-Aldrich). After 8 days of differentiation, cells were washed, fixed in $4 \%$ formalin for $1 \mathrm{~h}$, stained with an Oil Red $\mathrm{O}$ working solution and then incubated for an additional $1 \mathrm{~h}$ at room temperature. After washing 3 times with PBS, the cells were photographed with a light microscope (Olympus, Osaka, Japan). The size and number of lipid droplet were analyzed using Image Pro Plus 5.02. At least 10 different microscopic fields were used per well to determine adipocyte size and number. Next, $125 \mu \mathrm{l}$ isopropyl alcohol was added to each well, and the cells were maintained at room temperature for 5 min to stain the lipids with Oil Red O. Then, $100 \mu$ l of the eluate from each well was transferred to a 96-well plate, and the absorbance values at a 540-nm wavelength were measured using a spectrophotometer (Thermo Fisher Scientific, Inc.).

Statistical analysis. The relative band densities were quantified using Image Pro Plus 5.02. The data are presented as means \pm SD and were analyzed using the Student's t-test and one-way ANOVA with SPSS 13.0 software. P-values $<0.05$ were considered to represent statistically significant differences between groups.

\section{Results}

Effect of different concentrations of GLP-1 on 3T3-L1 preadipocyte viability. 3T3-L1 preadipocytes were treated with different concentrations of GLP-1 $(1,10,100$ or 1,000 nM) for $48 \mathrm{~h}$, and the cell viability was assessed by MTT assay. For GLP-1 concentrations between 1 and $100 \mathrm{nM}$, no effect on 3T3-L1 cell viability was observed. However, cell viability was decreased by $25 \%$ in cells treated with $1,000 \mathrm{nM}$ in comparison to the non-treated control $(\mathrm{P}<0.05)($ Fig. 1A). Therefore, the concentrations of 1,10 and $100 \mathrm{nM}$ were deemed suitable for use in the cell study. 

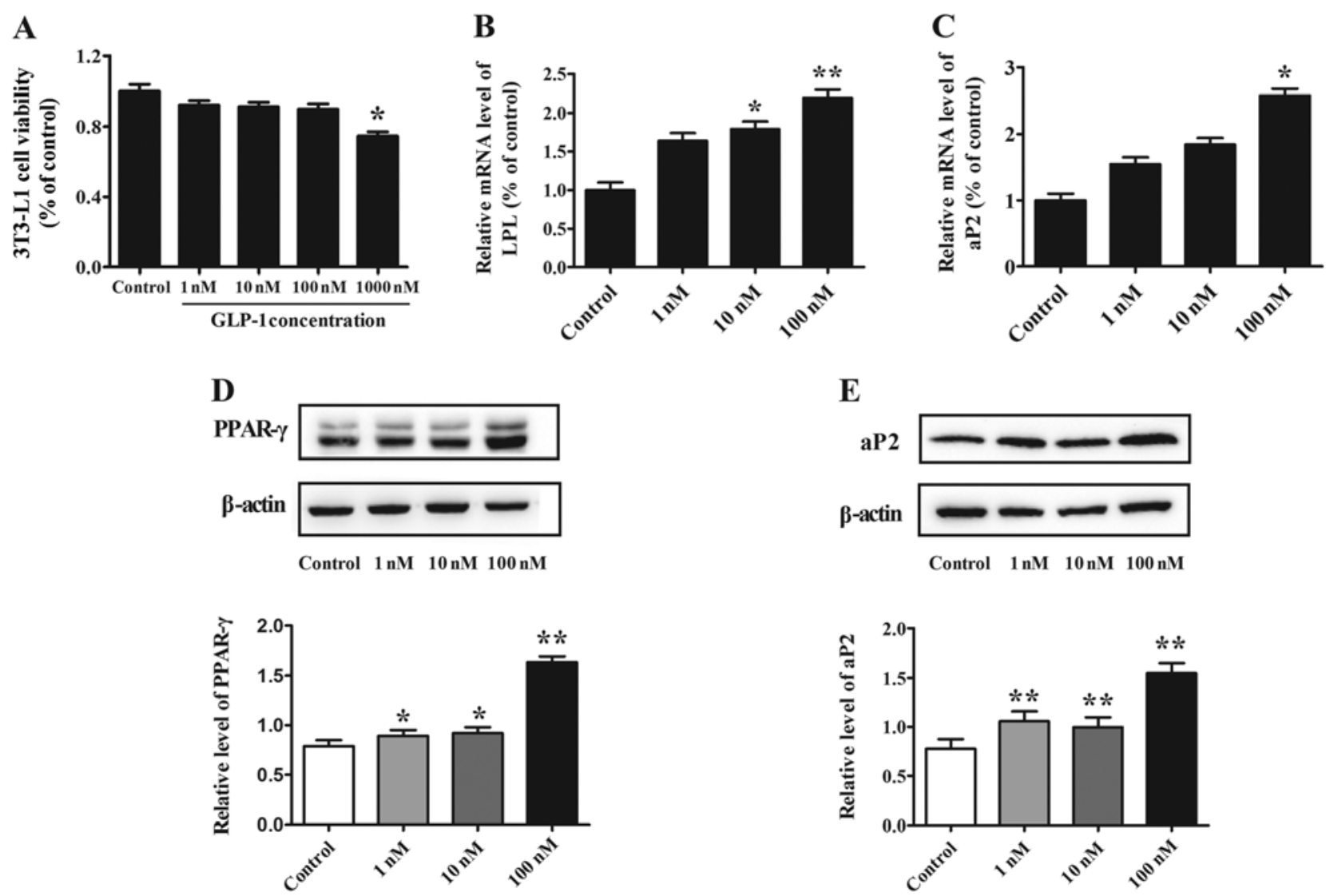

Figure 1. Effect of different concentrations of GLP-1 on the expression of adipocyte-specific markers. (A) 3T3-L1 preadipocytes were treated with different concentrations of GLP-1 during differentiation, and the cell viability was assessed by MTT assay. (B and C) The mRNA levels of the adipocyte-specific markers LPL and aP2 were analyzed by RT-PCR at day 8 of differentiation. (D and E) The protein expression levels of the transcription factors PPAR- $\gamma$ and aP2 were assessed by western blot analysis at day 8 of differentiation. The data shown represent the means \pm SD of $3-4$ independent experiments. ${ }^{*}<0.05$ vs. control; ${ }^{* *} \mathrm{P}<0.01$ vs. control. GLP-1, glucagon-like peptide 1 ; LPL, lipoprotein lipase; aP2, free fatty acid-binding protein 4 ; PPAR- $\gamma$, peroxisome proliferator activated receptor $\gamma$.

Effect of GLP-1 on adipocyte-specific markers during preadipocyte differentiation. To determine the effect of GLP-1 on 3T3-L1 preadipocyte differentiation, increasing concentrations of GLP-1 (1, 10 and $100 \mathrm{nM})$ were added to the cells for 8 days. Western blot analysis shown that the protein level of the transcription factor PPAR- $\gamma$ increased in a dose-dependent manner $(\mathrm{P}<0.05)$ (Fig. 1D) and that the maximal effect was reached at a concentration of $100 \mathrm{nM} \mathrm{GLP}-1(\mathrm{P}<0.01)$. We next examined the expression of the adipocyte-specific markers LPL and $\mathrm{aP} 2$ and found that these markers were also increased in a dose-dependent manner; the mRNA levels of LPL increased by 1.79 -fold $(\mathrm{P}<0.05)$ and 2.20 -fold $(\mathrm{P}<0.01)$ when cells were treated with 10 and 100 nM GLP-1, respectively, as compared to levels in the control (Fig. 1B). In addition, the mRNA level of aP2 increased by 2.58 -fold $(\mathrm{P}<0.05)$ at $100 \mathrm{nM}$ GLP-1 when compared to the level in the control (Fig. 1C). Furthermore, evaluation of the aP2 protein level demonstrated similar results when cells were treated with 100 nM GLP-1, which elicited the maximal effect $(\mathrm{P}<0.01)$ (Fig. 1E).

To further examine the effect of GLP-1 at varying times during differentiation, we added $100 \mathrm{nM}$ GLP-1 to the medium and harvested the cells at days $0,2,4,6$ and 8 . We observed that GLP-1 enhanced the mRNA levels of the transcription factors PPAR- $\gamma$ and $\mathrm{C} / \mathrm{EBP} \alpha$. In particular, the mRNA level of PPAR- $\gamma$ increased by $\sim 3$ - to 4-fold from day 2 to 6 (both $\mathrm{P}<0.05$ ) (Fig. 2A). The mRNA level of $\mathrm{C} / \mathrm{EBP} \alpha$ in the $100 \mathrm{nM}$ GLP-1 group was also enhanced markedly at day $4(\mathrm{P}<0.01)$ (Fig. 2B). In addition, GLP-1 enhanced the protein level of PPAR- $\gamma$ in a time-dependent manner (both $\mathrm{P}<0.05$ ) (Fig. 2C). Furthermore, we found that the amount of aP2 protein began to increase at day 4 of differentiation and then increased gradually at day 6 and 8 (Fig. 2D), and GLP-1 significantly increased the expression of aP2 when compared to that in the control (both $\mathrm{P}<0.01$ ).

Effect of GLP-1 on Akt, P38 and ERK1/2 signaling pathways during adipogenesis. Previous studies have shown that the Akt, P38 and ERK1/2 signaling pathways may be involved in adipogenesis. To identify whether GLP-1 affects these signaling pathways during adipogenesis, we evaluated the expression of phosphorylated-Akt (pAkt), phosphorylated-P38 (pP38) and phosphorylated-ERK1/2 (pERK1/2) at the early phase of differentiation. 3T3-L1 preadipocytes were incubated in differentiation medium containing $100 \mathrm{nM}$ GLP-1, and the cells were harvested at $0,15,30 \mathrm{~min}, 1,2,6,12$ and $24 \mathrm{~h}$ of culture. Western blotting showed that the level of pAkt increased rapidly at $15 \mathrm{~min}$ and that the pAkt level reached its maximum at $2 \mathrm{~h}$, which lasted for $24 \mathrm{~h}$. In contrast, the 
A

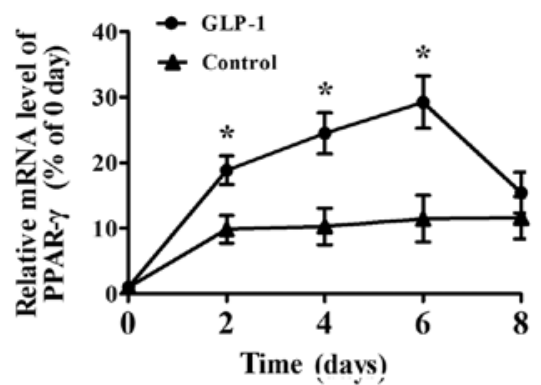

C
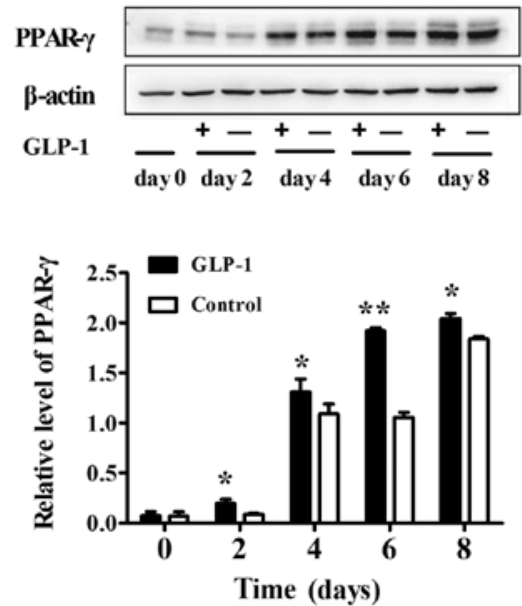

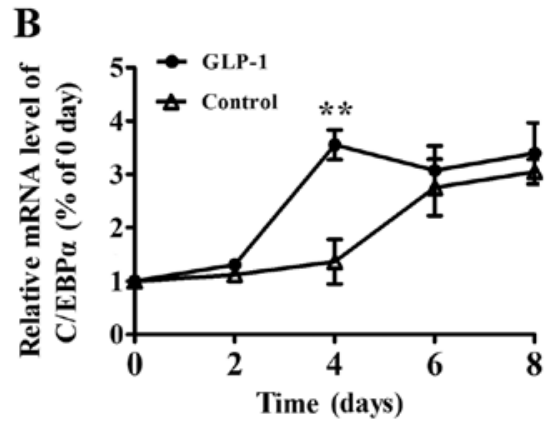

D
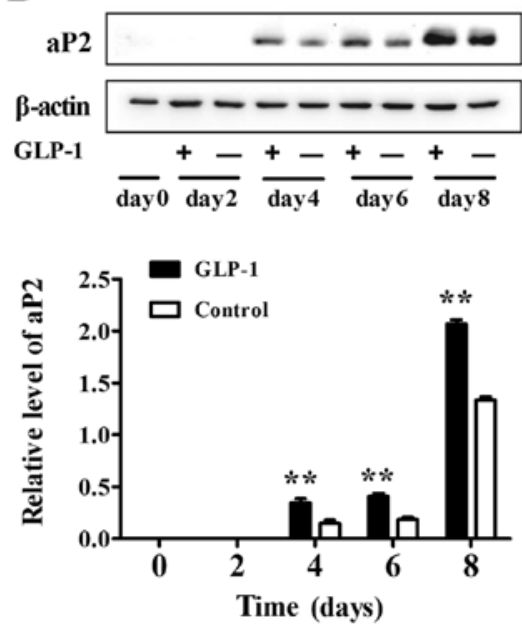

Figure 2. Effect of GLP-1 on the expression of adipocyte-specific markers during the entire differentiation period. GLP-1 (100 nM) was added to the differentiation medium, and the cells were harvested at days $0,2,4,6$ and 8 of culture. (A and B) The mRNA levels of PPAR- $\gamma$ and C/EBP $\alpha$ were analyzed by RT-PCR. (C and D) The protein levels of PPAR- $\gamma$ and aP2 were assessed by western blotting. The data shown represent the means \pm SD of 3-4 independent experiments. ${ }^{*} \mathrm{P}<0.05$ vs. control; ${ }^{* *} \mathrm{P}<0.01$ vs. control. GLP-1, glucagon-like peptide 1 ; PPAR- $\gamma$, peroxisome proliferator activated receptor $\gamma ; \mathrm{C} / \mathrm{EBP} \alpha, \mathrm{CCAAT} /$ enhancer-binding protein $\alpha ; \mathrm{aP} 2$, free fatty acid-binding protein 4 .

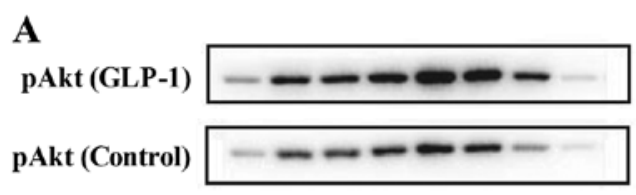

Akt
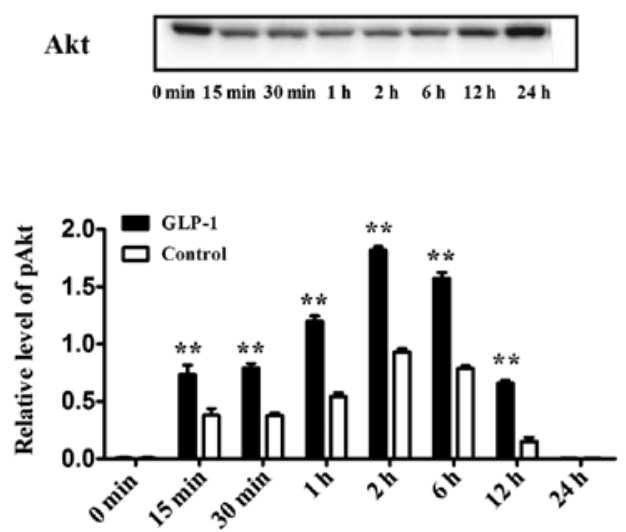

B

pP38 (GLP-1) - - - - -

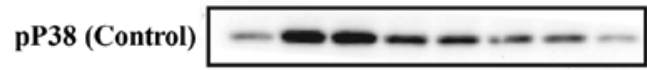

P38 - - - - - - -

$0 \min 15 \min 30 \min 1 \mathrm{~h} \quad 2 \mathrm{~h} \quad 6 \mathrm{~h} \quad 12 \mathrm{~h} \quad 24 \mathrm{~h}$

$\operatorname{pERK1/2(GLP-1)~}-\equiv=\Xi \equiv \equiv=$

pERK1/2 (Control) $=\equiv \equiv \equiv \equiv$

ERK $= \pm \equiv \equiv \equiv=$

$0 \min 15 \min 30 \min \quad 1 \mathrm{~h} \quad 2 \mathrm{~h} \quad 6 \mathrm{~h} \quad 12 \mathrm{~h} \quad 24 \mathrm{~h}$

Figure 3. Effect of GLP-1 on the Akt, P38 and ERK1/2 signaling pathways during the first $24 \mathrm{~h}$ of differentiation. GLP-1 (100 $\mathrm{nM})$ was added to the differentiation medium, and the cells were harvested at $0,15,30 \mathrm{~min}, 1,2,6,12$ and $24 \mathrm{~h}$ of culture. Western blot analyses were used to assess the protein levels of (A) pAkt and Akt, (B) pP38, P38, pERK1/2 and ERK1/2. The data shown represent the means \pm SD of 3 independent experiments. ${ }^{* * *}$ P $<0.01$ vs. control.

addition of $100 \mathrm{nM}$ GLP-1 significantly increased the expression of pAkt during the first $24 \mathrm{~h}$ of culture as compared to the control $(\mathrm{P}<0.01)$ (Fig. 3A). In addition, pP38 and pERK1/2 were also activated during the early phase of differentiation, while GLP-1 had no obvious effect on these expression levels (Fig. 3B). 
A
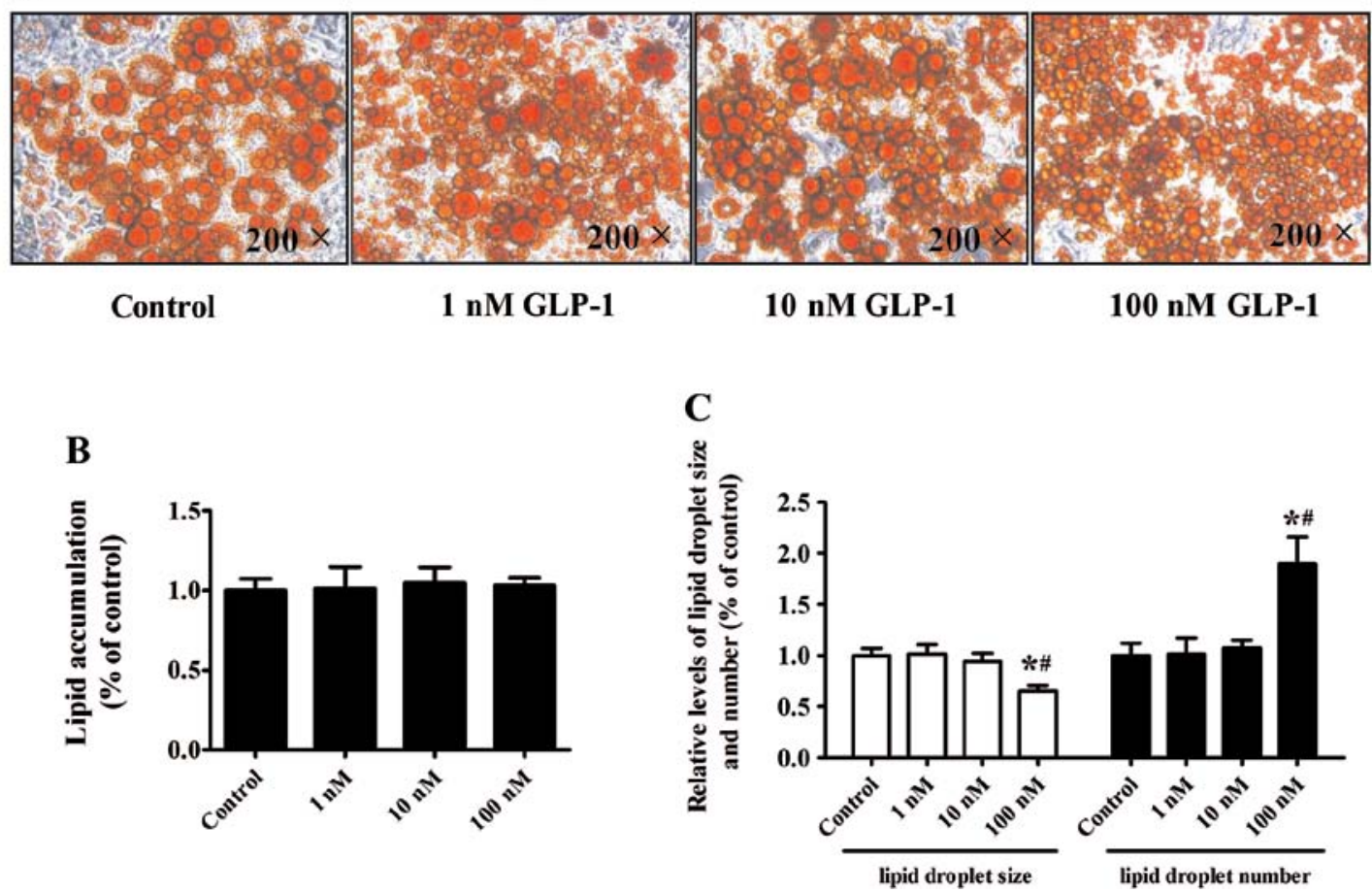

Figure 4. Effect of GLP-1 on lipid accumulation. 3T3-L1 preadipocytes were treated with increasing concentrations of GLP-1 during differentiation. At day 8 of differentiation, (A) the cells were stained with Oil Red O and (C) the size and number of lipid droplet were analyzed using Image Pro Plus 5.02. (B) Subsequently, $125 \mu \mathrm{l}$ of isopropyl alcohol was used to elute the Oil Red O, and lipid accumulation was quantified using a microplate reader. The data shown represent the means \pm SD of 3 separate experiments. ${ }^{*} \mathrm{P}<0.05$ vs. control; ${ }^{* *} \mathrm{P}<0.01$ vs. control; ${ }^{\sharp} \mathrm{P}<0.05$ vs. 1 and $10 \mathrm{nM}$ GLP-1. GLP-1, glucagon-like peptide 1 .

Effect of GLP-1 on lipid accumulation. We next performed Oil Red O staining to examine the effect of GLP-1 on lipid droplet accumulation. Differentiation of the 3T3-L1 preadipocytes was induced for 8 days with increasing doses of GLP-1 $(1,10$ or $100 \mathrm{nM}$ ). Surprisingly, isopropyl alcohol elutes of Oil Red $\mathrm{O}$ revealed that increasing concentrations of GLP-1 had no significant effects on lipid accumulation in comparison to the control cells (Fig. 4A and B) ( $\mathrm{P}>0.05)$. The lipid droplet size decreased markedly while the lipid droplet number increased in cultures treated with $100 \mathrm{nM}$ GLP-1, as compared to the control and other concentrations of GLP-1 $(\mathrm{P}<0.05)$ (Fig. 4C).

\section{Discussion}

Obesity is a major characteristic of metabolic syndrome; it is closely correlated with dyslipidemia, hyperglycemia and hypertension and is associated with an increased propensity for the development of cardiovascular disease (19). GLP-1 is an incretin hormone and has multiple biological effects against obesity and other metabolic diseases. Recent research has revealed that GLP-1 markedly improves insulin resistance in adipose tissue by reducing fat mass and adipocyte hypertrophy (18). In the present study, we demonstrated that GLP-1 regulates preadipocyte differentiation.

Preadipocyte differentiation is a complex process that is regulated by many transcription factors, particularly PPAR- $\gamma$ and CCAAT/enhancer-binding proteins such as $\mathrm{C} / \mathrm{EBP} \alpha$, $\mathrm{C} / \mathrm{EBP} \beta$ and $\mathrm{C} / \mathrm{EBP} \delta$. These transcription factors are the primary drivers of adipocyte gene induction during terminal differentiation (20). The expression of C/EBP $\alpha$ and PPAR- $\gamma$ cross-regulate each other through a positive feedback loop and induce the expression of downstream target genes, such as aP2 and LPL, which leads to the appearance of lipid droplets. These markers appear sequentially during differentiation, following a time-dependent expression pattern $(20,21)$. In the present study, we found that GLP-1 significantly promoted the expression of adipocyte-specific markers aP2 and LPL in a dose- and time-dependent manner. We also showed that GLP-1 enhanced the expression of the upstream transcription factors PPAR- $\gamma$ and $\mathrm{C} / \mathrm{EBP} \alpha$. Therefore, these results demonstrate that GLP-1 promotes adipogenesis by upregulation of adipocyte-specific markers aP2 and LPL in 3T3-L1 preadipocyte. Moreover, the transcription factors PPAR- $\gamma$ and C/EBP $\alpha$ are likely involved in this process.

We next investigated the potential signaling pathway involved in GLP-1-induced preadipocyte differentiation. The activation and phosphorylation of the Akt, P38 and ERK1/2 signaling pathways play a key role in the earliest phases of differentiation $(22,23)$. Akt signaling is indispensable for the regulation of preadipocyte and adipocyte number. It is also important for the regulation of insulin-stimulated metabolic pathways in human adipocytes (24). Furthermore, it has been reported that phosphorylation of Akt reduces the expression of forkhead transcriptional factor 1 (Foxo1), which is an antagonist of PPAR- $\gamma$, thus enhancing the expression of PPAR- $\gamma$ indirectly and promoting adipogenesis $(25,26)$. In addition, Akt phosphorylation activates C/EBP $\alpha$ during preadipocyte differentiation (21). Our findings revealed that for cells cultured in induction medium, Akt phosphorylation was rapidly induced after $15 \mathrm{~min}$ and reached a peak level at $2 \mathrm{~h}$, 
which was maintained for $24 \mathrm{~h}$ after the initial stimulation with induction medium. As compared to the non-treated control, treatment with $100 \mathrm{nM}$ GLP-1 significantly enhanced the level of pAkt. According to these findings, our results suggest that Akt phosphorylation may be involved in GLP-1-induced 3T3-L1 preadipocyte differentiation. Although the P38 and ERK1/2 signaling pathways are also important mediators of adipogenesis, GLP-1 treatment did not have a marked effect on these mediators in this study.

Previously, one study found that GLP-1 promoted the proliferation and cytoprotection of human bone marrowderived mesenchymal stem cells (hMSCs) but prevented cellular differentiation into adipocytes (27). However, a recent study suggests that GLP-1 promotes the proliferation and differentiation of preadipocytes by GLP-1R (28). The results of the present study support the latter view. We used 3T3-L1 preadipocytes as experimental subjects in this study because these cells are precursor of fat cells and are more specialized. Furthermore, we tested adipocyte-specific markers, including LPL and aP2, in comparison to previous studies to further analyze the effects of GLP-1 on preadipocyte differentiation. Notably, we found that the lipid droplet size decreased significantly while the lipid droplet number increased in cultures treated with $100 \mathrm{nM}$ GLP-1, as compared to the control and other concentrations. And the total lipid accumulation did not enhance markedly.

It has also been reported that an increase in the number of small subcutaneous adipocytes promotes lipid metabolism and insulin sensitivity $(9,29-31)$. The PPAR- $\gamma$ agonist TZD has been shown to stimulate preadipocyte differentiation, to increase the number of small subcutaneous adipose cells, to improve insulin sensitivity and to prevent excess lipid accumulation through the upregulation of the expression of Glu-4 and adiponectin (29,30). Ascofuranone, which has an anti-hyperlipidemia effect, can also increase the levels of PPAR- $\gamma$ and adiponectin in 3T3-L1 preadipocyte cells (31). Previous studies have revealed that GLP-1 increases insulin sensitivity by upregulating Glut-4, thus reducing macrophage infiltration, inhibiting inflammatory pathways and reducing fat mass in adipocytes $(29,30)$. Our results suggest an alternative mechanism whereby GLP-1 increases insulin sensitivity.

In conclusion, our data demonstrated that GLP-1 promotes 3T3-L1 preadipocyte differentiation by promoting the expression of the adipocyte-specific markers LPL and aP2 and the transcription factors PPAR- $\gamma$ and $\mathrm{C} / \mathrm{EBP} \alpha$. Moreover, activation of the Akt signaling pathway may be involved in this process. GLP-1 also increased the numbers of small adipocytes, which may increase insulin sensitivity and consequently have a positive effect against obesity.

\section{Acknowledgements}

The present study was supported by the National Natural Science Foundation of China (no. 81100617), the Medical and Health Science and Technology Development Projects of Shandong Province (2011HD005), the National Science and Technology Support Plan (2009BAI80B04), the Natural Science Foundation of Shandong Province (ZR2012HM014), the Chinese Diabetes Society Key Projects (07020470055), the
International Science and Technology Projects of Shandong Province (2010GHZ20201), the Science and Technology Star Project of Jinan Sincere and Technology Bureau (20100318), the Innovation Foundation of Shandong University (2009TS054) and the Business Plan of Jinan Students Studying Abroad (20110407).

\section{References}

1. Hossain P, Kawar B and El Nahas M: Obesity and diabetes in the developing world - a growing challenge. N Engl J Med 356: 213-215, 2007.

2. Shi H, Akunuru S, Bierman JC, et al: Diet-induced obese mice are leptin insufficient after weight reduction. Obesity 17: 1702-1709, 2009.

3. Seale P and Lazar MA: Brown fat in humans: turning up the heat on obesity. Diabetes 58: 1482-1484, 2009.

4. Dahlman I and Arner P: Obesity and polymorphisms in genes regulating human adipose tissue. Int J Obes 31: 1629-1641, 2007.

5. Sun K, Kusminski CM and Scherer PE: Adipose tissue remodeling and obesity. J Clin Invest 121: 2094-2101, 2011.

6. Cristancho AG and Lazar MA: Forming functional fat: a growing understanding of adipocyte differentiation. Nat Rev Mol Cell Biol 12: 722-734, 2011.

7. Spalding KL, Arner E, Westermark PO, et al: Dynamics of fat cell turnover in humans. Nature 453: 783-787, 2008

8. Tchoukalova YD, Votruba SB, Tchkonia T, et al: Regional differences in cellular mechanisms of adipose tissue gain with overfeeding. Proc Natl Acad Sci USA 107: 18226-18231, 2010.

9. Hoffstedt J, Arner E, Wahrenberg H, et al: Regional impact of adipose tissue morphology on the metabolic profile in morbid obesity. Diabetologia 53: 2496-2503, 2010.

10. Koenen TB, Tack CJ, Kroese JM, et al: Pioglitazone treatment enlarges subcutaneous adipocytes in insulin-resistant patients. J Clin Endocrinol Metab 94: 4453-4457, 2009.

11. Veilleux A, Caron-Jobin M, Noel S, et al: Visceral adipocyte hypertrophy is associated with dyslipidemia independent of body composition and fat distribution in women. Diabetes 60: 1504-1511, 2011.

12. Meier JJ: GLP-1 receptor agonists for individualized treatment of type 2 diabetes mellitus. Nat Rev Endocrinol 8: 728-742, 2012.

13. Kielgast U, Holst JJ and Madsbad S: Antidiabetic actions of endogenous and exogenous GLP-1 in type 1 diabetic patients with and without residual $\beta$-cell function. Diabetes 60: 1599-1607, 2011.

14. Ben-Shlomo S, Zvibel I, Shnell M, et al: Glucagon-like peptide-1 reduces hepatic lipogenesis via activation of AMP-activated protein kinase. J Hepatol 54: 1214-1223, 2011.

15. Chai W, Dong Z, Wang N, et al: Glucagon-like peptide 1 recruits microvasculature and increases glucose use in muscle via a nitric oxide-dependent mechanism. Diabetes 61: 888-896, 2012.

16. Gao H, Wang X, Zhang Z, et al: GLP-1 amplifies insulin signaling by up-regulation of IR $\beta$, IRS- 1 and Glut 4 in 3T3-L1 adipocytes. Endocrine 32: 90-95, 2007.

17. Lee YS, Park MS, Choung JS, et al: Glucagon-like peptide-1 inhibits adipose tissue macrophage infiltration and inflammation in an obese mouse model of diabetes. Diabetologia 55: 2456-2468, 2012.

18. He M, Su H, Gao W, et al: Reversal of obesity and insulin resistance by a non-peptidic glucagon-like peptide-1 receptor agonist in diet-induced obese mice. PLoS One 5: e14205, 2010.

19. Bass J and Takahashi JS: Circadian integration of metabolism and energetics. Science 330: 1349-1354, 2010.

20. Cristancho AG and Lazar MA: Forming functional fat: a growing understanding of adipocyte differentiation. Nat Rev Mol Cell Biol 12: 722-734, 2011.

21. Kim GS, Park HJ, Woo JH, et al: Citrus aurantium flavonoids inhibit adipogenesis through the Akt signaling pathway in 3T3-L1 cells. BMC Complement Altern Med 12: 31, 2012.

22. Choi SS, Cha BY, Iida K, et al: Honokiol enhances adipocyte differentiation by potentiating insulin signaling in 3T3-L1 preadipocytes. J Nat Med 65: 424-430, 2011.

23. Zhang M, Ikeda K, Xu JW, et al: Genistein suppresses adipogenesis of 3T3-L1 cells via multiple signal pathways. Phytother Res 23: 713-718, 2009.

24. Fischer-Posovszky P, Tews D, Horenburg S, et al: Differential function of Akt1 and Akt2 in human adipocytes. Mol Cell Endocrinol 358: 135-143, 2012. 
25. Polvani S, Tarocchi $M$ and Galli A: PPAR $\gamma$ and oxidative stress: Con $(\beta)$ catenating NRF2 and FOXO. PPAR Res 2012: 641087, 2012 .

26. Dowell P, Otto TC, Adi S and Lane MD: Convergence of peroxisome proliferator-activated receptor $\gamma$ and foxol signaling pathways. J Biol Chem 278: 45485-45491, 2003.

27. Sanz C, Vázquez P, Blázquez C, Barrio PA, Alvarez Mdel M and Blázquez E: Signaling and biological effects of glucagonlike peptide 1 on the differentiation of mesenchymal stem cells from human bone marrow. Am J Physiol Endocrinol Metab 298: E634-E643, 2010.

28. Challa TD, Beaton N, Arnold M, et al: Regulation of adipocyte formation by GLP-1/GLP-1R signaling. J Biol Chem 287: 6421-6430, 2012.
29. Kang JG, Park CY, Ihm SH, et al: Mechanisms of adipose tissue redistribution with rosiglitazone treatment in various adipose depots. Metabolism 59: 46-53, 2010

30. Dubuisson O, Dhurandhar EJ, Krishnapuram R, et al: PPARgamma-independent increase in glucose uptake and adiponectin abundance in fat cells. Endocrinology 152: 3648-3660, 2011.

31. Chang YC and Cho HJ: Ascofuranone stimulates expression of adiponectin and peroxisome proliferator activated receptor through the modulation of mitogen activated protein kinase family members in 3T3-L1, murine pre-adipocyte cell line. Biochem Biophys Res Commun 422: 423-428, 2012. 